rança laboratoriais e, que depois de figurarem na exposição se destinaram a serem afixadas no próprio laboratório. A ligação entre as duas disciplinas (Química e Educação Visual) foi exemplar, e o sentido proposto, de representação e comunicação, ao nivel dos alunos utentes do laboratório, também resultou satisfatoriamente. A execução gráfica dos cartazes ajudou à interiorização dos princípios de segurança e estes deram à disciplina de Educação Visual um tema, para além do mais, ligado aos interesses dos alunos e da matéria tratada na disciplina de Química. Isto é, resumidamente, as disciplinas deram as mãos!

Outro destaque significativo e que valorizou substancialmente a exposição, foi a inclusão de um aparelho e de uma maquete para aproveitamento da energia solar.

$\mathrm{O}$ que dizer mais da exposição, dos trabalhos em si individualmente, e do seu somatório - do conjunto? apenas que resultou - foi expressão do interesse e do es- forço dos alunos - e que têm a marca das suas mãos, da sua sensibilidade - olhos adolescentes abertos para o mundo.

Não nos interessou tanto o aspecto publicitário ou de marketing, nem tão pouco a qualidade gráfica dos objectos de consumo, mas a experiência concreta de uma escola viva em que não sejam só os livros os únicos manaciais ou depósitos (às vezes estagnados) do saber. Interessou-nos mais que as paredes fossem livros e que os alunos fossem também os autores, que o foram de facto. Procurámos que eles ouvissem a sua voz colectiva. Entendessem que também falam, que também vêem, que também pensam. É a descoberta, sempre reticente mas também envolta em mantos de surpresa - as cores coloridas da descoberta.

Foi um voo - talvez o primeiro - mas, certamente, não o último.

\section{DO USO DA HISTÓRIA DA QUÍMICA NO SEU ENSINO}

«É no amor ao passado que nos comprometemos com o presente e encontramos esperanças para o futuro"

Merle Shein

\author{
A.M. Amorim da Costa \\ Departamento de Química \\ Universidade de Coimbra \\ 3000 COIMBRA - PORTUGAL
}

tendo como inútil, desnecessária e até perda de tempo o procurar conhecer os caminhos gloriosa ou ingloriosamente trilhados, tidos como acidentes de percurso, na sistematização da ciência em causa.

Temos de reconhecer, que essa mentalidade se pode tornar não só perniciosa como deformadora.

Naturalmente, a história das Ciências da natureza não tem a mesma função na formação de um cientista qual a da história da filosofia ou da teologia na formação de um filósofo ou de um teólogo. Com efeito, enquanto em filosofia ou em teologia os diversos sistemas desenvolvidos ao longo dos tempos valem pelos postulados em que assentam podendo, por isso, nunca perder totalmente a sua actualidade histórica, ou, na pior das hipóteses, a sua actualidade lógica, na história das ciências na natureza as teorias de outrora, em geral, não têm qualquer valor enquanto históricas: se cuntinuam actuais encontram-se incorporadas (ainda que, por vezes, não satisfatoriamente enquadradas) nos manuais correntes, sem que se torne necessário qualquer tratado histórico para que sejam conhecidas; se perderam actualidade, do ponto de vista estritamente científico, deixaram de ter qualquer interesse.

Não é, porém, a este nível que deve ser verdadeiramente encarada a actualidade da história das ciências como parte integrante da formação do cientista. É que num mundo em que domina cada vez mais o especialista desarticulado dum saber mais geral, não se pode deixar 
de ficar hororizado ao ver surgir nos nossos tempos uma nova raça de homens robots, adeptos de uma ciência sem consciência. Uma educação meramente positivista não pode deixar de formar uma juventude sem alma que apenas crê em números e naquilo que se possa contar, medir e pesar; uma juventude "cheia de uma ciência empírica, mas destituída de cultura humanística, qual a que em nossos dias sai de todas as escolas, atrofiada por uma embrutecedora especialização do ensino", como diria Oliveira Martins nos finais do século passado.

$\mathrm{O}$ estudo da história das ciências é útil para a formação do homem de ciência fazendo dele um filósofo da natureza e não simples artesão especializado, pois que a verdadeira cultura de uma ciência é algo mais que a sua aplicação no mundo exterior devendo incluir uma verdadeira crítica sobre o conjunto de conhecimentos que a formação, a meditação sobre os fundamentos dos mesmos e ainda uma confrontação com outros aspectos da realidade que se situam para além dela. É que a história das ciências, como qualquer história, não é, nem pode ser, simples enumeração do passado; é necessariamente também interpretação e juizo. E falha redondamente se o não for.

\section{ANTIDOGMATISMO E ANTI-IDOLATRISMO}

As vantagens advenientes do estudo da história das ciências adentro duma orientação paralela à que se acaba de delinear são incalculáveis e compreendem, muito concreta e universalmente, uma proteç̧ão eficazmente sã contra todo o dogmatismo científico e uma protecção não menos benéfica e necessária contra a super- ou subestimação do sábio individual.

$\mathrm{Na}$ verdade, o estudo da história leva naturalmente a uma atitude que não é nunca nem de riso nem de choro perante o passado, mas antes de sã compreensão. Ideias que hoje se revelam à saciedade como absurdas, foram noutras épocas tidas como plausiveis e verosímeis. E quantos erros de antanho não foram os reais indicadores dos verdadeiros caminhos por onde se veio a enveredar posteriormente! Quantos erros passados não estavam muito mais prenhes de inteligência do que muitas ideias absolutamente correctas e exactas! Muitas vezes não é por mera estupidez que nos enganamos e nos prendemos tenazmente a soluçðes erradas, mas antes por um excesso de sagacidade!

Do ponto de vista histórico, os erros de antanho podem ser tão importantes como os mais brilhantes sucessos, do mesmo modo que as figuras habitualmente consideradas e tratadas como de segundo plano merecem e é-lhes devida a melhor das atençōes. Só o sentido histórico do verdadeiro progresso científico nos dará, todavia, a verdadeira dimensão da ciência que cultivamos, com a importância relativa do que nela houve e há de são ou errado. O Físico moderno não tomará nunca a sério a explicação da queda dos graves ou a combinação dos elementos tal qual Aristóteles as explica. Todavia, se possui autêntico sentido histórico que lhe confere verdadeira sabedoria, nunca irá ao ponto de ridicularizar essas mesmas teorias, nem sequer até ao ponto de as considerar meramente infantis. Se não faz sentido considerar a arte primitiva como uma manifestação infantil do espírito humano, nem faz sentido que um teólogo ou um filósofo considerem, cada qual no seu tempo, Santo Agostinho ou Platão como crianças em teologia ou em filosofia, também não faz sentido julgar ingénuas as teorias científicas doutras épocas vistas à luz dos dados e das ideias de hoje.
As teorias mais absurdas do ponto de vista moderno podem ter sido as mais engenhosas e justificadas pelos factos dos tempos em que apareceram e reinaram. Só uma análise histórica verdadeiramente perspicaz e porventura completa as poderá julgar em todo o seu valor.

$\mathrm{Se}$ os cientistas actuais debruçados sobre o mundo exterior conseguem ver muito mais longe do que o conseguiram os seus predecessores não é, necessariamente, porque sejam maiores ou mais inteligentes, mas sim, em boa verdade, porque o seu apoio sobre os ombros de geraçð̄es e geraçס̄es passadas lhe permitem uma visão muito mais vasta.

Por outro lado, não é raro deparar-se com uma "agiografia" científica e deixar-se entusiarmar desmesuradamente pelos feitos dos grandes génios reduzindo todos os demais a seus satélites na mais completa e injusta omissão de tudo quanto eles ficaram a dever a toda uma pleíade de cientistas porventura perdidos em completo anonimato. A história mostra que a maioria dos grandes sábios foram muito mais frutos da época em que viveram do que muitas vezes o imaginam "historiadores" que se deixam guiar ou arrastar por pesada dose de idolatrismo e fantasia. E também não é raro deparar-se com uma mentalidade totalmente oposta, a daqueles que arrogantemente afirmam que a história teria exactamente o mesmo curso sem este ou aquele grande génio, não os considerando como a causa do desenvolvimento da ciência que lhes é geralmente atribuído, defendendo antes que foram arrastados por esse mesmo desenvolvimento, tendo-se pura e simplesmente mantido atentos ao desenrolar dos acontecimentos sem se deixarem ultrapassar por eles.

Qualquer dos dois extremos deve ser evitado. Lavoisier não foi, certamente, o produto dos seus percursores; mas não foi também o herói que nada deve a quantos o precederam, bem como a muitos dos seus contemporâneos com quem trabalhou e trocou muitas vezes preciosas impressőes. Se é certo que muitas descobertas científicas só ocorreram quando o "tempo estava maduro" para as acolher, não é memos certo que muitas outras só não ocorreram mais cedo porque tiveram de esperar pelo "génio" de olhar sagaz que foi capaz de as detectar.

\section{FUNÇÃO PROPEDÊUTICA DA HISTÓRIA DA QUÍMICA}

Certos de que o ensino da história da ciência não pode ser relegado para uma posição de total omissão sem se incorrer em autêntica atitude pseudo científica, impõe-se definir o justo peso que lhe deva ser atribuído para que não degenere também em prejuízo da real formação científica. E o que vamos tentar em relação ao ensino da Química.

Começaremos por dizer que nos limitaremos ao ensino da Química no nosso país, e ao ensino a nível secundário, por ser este o primeiro ensino da Química com que o estudante se defronta e que, por consequência, mais determinantemente o marca para toda a sua vida, para bem e para mal, sob o ponto de vista de orientação; e ainda por ser o ensino a nível do secundário aquele em que é possível uma intervenção mais estandardizada em moldes de orientação oficial. 
O actual programa de Química do Ensino secundário não é certamente o melhor que se poderia desejar para uma boa formação química a esse nivel; e não o é quer no seu conteúdo, quer no desenvolvimento geral do mesmo. Apesar de tudo, da sua análise global seria de esperar que quando minimamente cumprido, dotasse o país com grupos de jovens atraídos com certo entusiasmo para a ciência Quimica em que esse programa os iniciou. Não é isso, porém, que se verifica, generalizadamente, ao longo de todo o país. Por falta de verdadeira motivação, decora-se um certo número de factos descritos nos Manuais e um certo número de fórmulas esquisitas que se tem dificuldade em manusear e recitam-se até, possivelmente a jeito de receita culinária, várias aplicaçøes e usos da quimica em processos industriais agarrados nos seus tentáculos. Mas termina-se sem grande entusiamo pela disciplina, sem verdadeiro interesse por ela e com a ideia generalizada de que se trata duma matéria "chata" e intragável. Quanto ao seu objectivo verdadeiro, o seu ensino é um fracasso na grande, grande maioria das nossas escolas do Ensino secundário.

E a culpa não pode ser atirada pura e simplesmente para cima do conjunto de alunos que compóem os cursos em que é ministrada, onde há certamente muito e muito aluno esperto e inteligente para além de possiveis pequenas minorias de "menos bom". E também não creio que se possa atirar essa culpa pura e simplesmente para cima de uma menos satisfatória preparação científica e/ou psicopedagógica dos professores que na grande generalidade não é tão deficiente quanto o pressupð̄em os resultados concretos de ano após ano. Não. A grande falha está, julgo, no modo como a Química é apresentada ao aluno; está, numa palavra, na metodologia seguida no seu ensino.

$\mathrm{Na}$ grande maioria das nossas escolas, ensina-se a Química como se se tratasse dum exercício mental, dando toda a atenção à actualidade das teorias e modelos que constituem o seu conteúdo, sem qualquer preocupação pelo enquadramento passado, presente e futuro de tais teorias e modelos. Não há a mínima preocupação em referir o modo "vivo" como se chegou ao presente estado do conhecimento químico, nem, a inserção mínima deste no contexto dos problemas do nosso dia a dia. Expðem-se as últimas descobertas e teorias sem mesmo fazer notar, muitas vezes, de que se trata de matéria sujeita a constante reexame e frequentemente as teorias mais populares de hoje serão olhadas com mera complacência e uma certa dose de diversão pelas geraçðes de amanhã.

$E$ a reacção natural de milhares de estudantes de quimica é que esta nada tem a ver com as suas vidas, nem com a vida de qualquer ser humanó. E daí a também natural não motivação e falta de interesse final.

É extremamente importante que o estudante se consciencialize que a química é uma disciplina muito mais dinâmica que estática. Os fenómenos de natureza cosmoquímica, geoquímica ou bioquímica não ocorrem apenas desde que o homem começou a debruçar-se sobre eles procurando sistematicamente compreendê-los, num estudo que constitui a ciência química; ocorrem sim desde épocas muito mais remotas, perdendo-se a sua origem nas mais pré-históricas eras do universo, e continuarão a ocorrer mesmo que o homem se extinga e deixe de debruçar-se sobre eles. A ciência química foi criada pelo homem desejoso de conhecer a natureza das transformaçð̋es materiais que ocorrem em si e à sua volta; insere-se pois, no próprio empreendimento histórico do ser huma- no, e é parte integrante da sua actividade. O conhecimento que a constitui tem a sua origem muito mais na curiosidade humana sobre a natureza das transformaçðes quimicas que o envolvem e cercam do que numa actividade de pendor ou cariz lógico.

À História da Química cabe a tarefa de mostrar ao estudante como a química é realmente parte integrante da actividade humana. E daí que ela não possa ser totalmente ignorada nos currícula do ensino da química.

Há, certamente, modos variados de ensinar a História da Química, do mesmo modo que há variados modos de a ignorar ou deturpar. Por razões práticas, não pugnaremos certamente, a nível do Ensino secundário, por uma disciplina independente da própria disciplina de Química, não importa se a nível introdutório, médio ou avançado. Pugnaremos sim pela necessidade de introduzir historicamente, nos seus diversos capítulos, o conteúdo do programa de Química de modo a que o estudante possa compreender o modo de evolução dos conceitos que lhe são apresentados. Embora haja conceitos que se prestam mais facilmente a um tratamento histórico que outros, pode afirmar-se que apenas um pequeno número deles poderão ser devidamente entendidos caso não sejam adequadamente enquadrados no contexto histórico em que se desenvolveram.

Nem por se destinarem a jovens numa idade particularmente sedenta de aventura e curiosa de história, os Manuais de química do Ensino secundário que hoje temos em Portugal são de todo pobres neste aspecto, com a agravante de se ter recuado significativamente, neste particular, em relação a Manuais em vigor há alguns anos(1).

Seria altamente salutar que na sua primeira iniciação à Química, qual é a que o estudante recebe no Ensino secundário, ficasse bem marcada a saga de todos esses homens que ao longo de séculos dedicaram o melhor da sua vida procurando denodadamente, muitas vezes como quem tacteia e caminha às apalpadelas na escuridão, as causas, e através delas, as leis que governam os mais variados fenómenos químicos que tantas vezes teimam em se não deixar compreender em toda a sua vastidão. Uma saga que passa pela frenética e infrutífera busca do ouro pelos alquimistas, pela procura do elixir de longa vida, pela luta renhida contra a superstição médica, pela tentativa de séculos de descoberta da natureza do fogo, pelo nascimento e morte da nociva teoria do flogisto e, simultaneamente no tempo, pela descoberta do oxigénio, a compreensão da natureza da combustão, a descoberta da composição da atmosfera e da água; uma saga que passa, já muito mais perto dos nossos dias, pela controvérsia em torno das teorias de Dalton sobre a natureza dos átomos, minúsculos e invisíveis, e pela descoberta de algumas leis básicas do comportamento químico de átomos e moléculas, com a controvérsia entre Berthollet e Proust sobre a validade da lei da composição constante; uma saga que passa ainda pela definição de uma nomenclatura sensivel baseada nos símbolos que hoje usamos de preferência aos hieróglifos usados na antiguidade e a simbologia muito mais complexa usada pelos alquimistas, bem como pelo estabelecimento da primeira, ainda que pequena, lista de pesos atómicos e pela procura de novos elementos, em parte instigada pelas previsð̄es de tipo quase profético, de Mendeleiev; uma saga que passa, finalmente, para não nos demorarmos mais numa longa enumeração possível, pela batalha travadas em torno dos iōes de Arrhénius que levou a uma melhor compreensão dos fenómenos de ionização, pela desco- 
berta dos raios $\mathrm{X}$, do rádio, dos electrões, dos protões, dos neutrões e demais partículas subatómicas, com o assalto final, já nos nossos dias, àquilo que poderíamos chamar o último reduto do átomo, a fissão e fusão nucleares, que colocoù nas mãos do Homem não só esse imenso gigante de Bem e de Mal que é a energia atómica, como também o segredo por que almejaram os alquimistas durante tantos séculos ao esfalfarem-se na procura da Pedra Filosofal, a transmutação dos metais vis em metais nobres.

Nada melhor para interligar as diferentes áreas do curriculum escolar da química, conferindo-lhe uma unidade viva e aliciante, do que uma boa visão histórica dos assuntos que as compōem, através da qual se evidencie e realce, ainda que em linhas muito genéricas, como os problemas nasceram e como evoluíram até ao estágio em que hoje os temos.

Não se trata, certamente, de tarefa fácil; mas é repto e desafio constantemente lançado a quantos do ensino da química desejam fazer sua missão.

E terminaria citando Einstein: «criar uma nova teoria não é como destruir um celeiro em ruínas para em seu lugar construir um arranha-céus. É antes como subir ao alto de uma montanha, numa contínua descoberta de novos e mais vastos horizontes, com inesperadas conexठ̃es com o ponto donde partimos e do rico ambiente em que se insere».
(1) Este recuo é nítido quando se compara, por exemplo, o Compêndio de Química para o 6. ${ }^{\circ}$ e 7. ${ }^{\circ}$ Anos Liceais, de Alice M. MAGALHÃES e Túlio L. Tomaz (Ed. Avis, Porto, 1963) com qualquer dos Manuais hoje em circulação, para qualquer dos niveis do secundário, podendo destacar-se:

- M. Helena Côncio F. Silva Sousa, Estrutura Atómica $e$ Tabela Periódica (Almedina, Coimbra, 1975);

- Id., Ligação Química. Estrutura e Propriedades (Almedina, Coimbra, 1975);

- C. Correa e A. Nunes, Química, $10{ }^{\circ}$ Ano de Escolaridade (Porto Editora, 1980);

- A. Amaral e C.M.M.S. Correa, Química, $12 .^{\circ}$ Ano de Escolaridade (Porto Editora, 1982): Vol. I - Matéria e Radiação; Vol. II - Reaccōes Química;

- V.M.S. GIL e A.C. CARDOSo, Fundamentos da Estrutura e Propriedades da Matéria (Almedina, Coimbra, 1981);

- Id., Dinâmica e Transformação da Matéria (Almedina, Coimbra, 1981);

- A. Romão Dias, H. Beckert e M.E. MAiA, Ligação Química (Ed. Textos Pré-Universitários, Lisboa);

No livro de Alice M. Magalhães e Túlio L. Tomaz encontramos todo um primeiro capítulo devotado a uma notícia histórica da evolução da Quimica até Lavoisier, bem como um enquandramento histórico francamente positivo e atraente das teorias de Dalton, Avogadro, Arrhénius, Berthollet, etc.; e encontramos, a cada passo, textos de interesse histórico, de leitura agradável e interessante tais como o Texto da Tábua de Esmeralda e textos vários de Lavoisier, Paracelso, etc. Em qualquer dos Manuais agora em circulação tudo quanto encontramos, do ponto de vista da história, é, praticamente, uma ladainha de nomes e/ou fotografias de personagens históricos ligados à Química, com as datas que referenciam a sua existência, mas, genericamente, sem qualquer enquadramento verdadeiramente histórico da sua contribuição para o fazer da Quimica. E já nem falamos da pouca precisão histórica com que mesmo esta apresentação sumária muitas vezes é feita: uso indescriminado de nomes latinos e/ou portugueses; não referência a diferenças fundamentais das teorias a que aparecem associados (v.g., Demócrito, Lucrécio e Dalton associados de igual modo ao atomismo), etc.

\section{LABORATÓRIO NACIONAL DE ENGENHARIA E TECNOLOGIA INDUSTRIAL}

DEPARTAMENTO DE TECNOLOGIA E DE INDÚSTRIA QUIMICA CENTRO DE FORMACุÃO TÉCNICA

em colaboração com a

FACULDADE DE FARMÁCIA DE COIMBRA

\section{PROGRAMA PRELIMINAR}

1. as Jornadas de Plantas Aromáticas e Óleos Essenciais 17-18-19 Novembro 1983

\section{ORGANIZADOS POR:}

- Laboratório Nacional de Engenharia e Tecnologia (LNETI)

- Departamento de Tecnologia e de Indústrias Químicas e Centro de Formação Técnica.

- Faculdade de Farmácia de Coimbra

TEMAS:

- Botânica das labíadas e suas potencialidades;

- As plantas aromáticas em terapêutica, perfumaria, cosmética e alimentação;

- Tecnologias de extraç̧ão e controlo de qualidade;

- Hidrocarbonetos terpénicos na síntese de produtos aromáticos:

\section{PARTICIPANTES:}

Podem ser participantes os Universitários, Investigadores, Farmacêuticos e Industriais de oleos essenciais e plantas aromáticas.

O preço da inscrição será de $8000 \$ 00$, que inclue a documentação, almoços (dias 17 e 18) e jantar de encerramento.

\section{COMUNICAÇÕES:}

Os participantes podem apresentar comunicaçøes sobre os temas mencionados as quais deverão ser entregues até 15 de Setembro num dos seguintes locais:

- Faculdade de Farmácia de Coimbra - Secção Farmacognosia - Telef. 23681

- Departamento de Tecnologia de Indústrias Quimicas - Av. das Palmeiras, 2745 (Queluz de

Baixo) - Tefefs. $952186 / 954281$.

\section{OUTRAS INDICAÇÕES:}

Nas "1. as Jornadas de Plantas Aromáticas e Óleos Essenciais" que terão lugar nos dias 17, 18, 19, na Faculdade de Farmácia de Coimbra, intervirão, entre outros, os seguintes especialistas franceses e portugueses:

- Prof. Maurice Jacob - Faculdade de Farmácia da Universidade de Montpellier

- Dr. Eng. Louis Peryon - Director de Investigação de Lautier Aromatique

- Prof. João Amaral Franco - Instituto Superior de Agronomia

- Prof. António Proença da Cunha - Faculdade de Farmácia de Coimbra

- Dr. ${ }^{a}$ Maria Margarida do Carmo - Investigadora do LNETI.

As jornadas incluirão sessð̃es plenárias e de comunicaçðes com início às $9.30 \mathrm{~h}$ do dia $17 \mathrm{e}$ encerramento às 17.00 h do dia 19 de Novembro.

Até 15 de Outubro será enviado o programa definitivo.

\section{IMFORMAÇÕES:}

Qualquer informação adicional pode ser solicitada ao CENTRO DE FORMAÇĀO TÉCNICA DO LNETI

- Praça do Principe Real, 19 - 1200 LISBOA

- Telefs. $323387 / 366308 / 363200$. 